\title{
Efficacy and Safety of Long-Term Thiopurine Maintenance Treatment in Japanese Patients With Ulcerative Colitis
}

\author{
Satoshi Yamada ${ }^{1}$, Takuya Yoshino ${ }^{1}$, Minoru Matsuura ${ }^{1}$, Masamichi Kimura $^{1}$, Yorimitsu Koshikawa , \\ Naoki Minami ${ }^{1}$, Takahiko Toyonaga ${ }^{2}$, Yusuke Honzawa ${ }^{1}$, Hiroshi Nakase ${ }^{1}$ \\ Department of Gastroenterology and Hepatology, Graduate School of Medicine, Kyoto University', Kyoto, The Third Department of Internal \\ Medicine, Kansai Medical University', Osaka, Japan
}

Background/Aims: The long-term clinical outcomes of patients with bio-naive ulcerative colitis (UC) who maintain remission with thiopurine are unclear. The aim of this study was to assess the long-term efficacy and safety of maintenance treatment with thiopurine in UC patients. Methods: This was a retrospective observational cohort analysis conducted at a single center. Between December 1998 and August 2013, 59 of 87 patients with bio-naive UC who achieved remission after induction with treatments other than biologics were enrolled. Remission maintenance with thiopurine was defined as no concomitant treatment needed other than 5-aminosalicylate without relapse. We assessed the remissionmaintenance rate, mucosal healing rate, colectomy-free rate, and treatment safety in UC patients who received thiopurine as maintenance treatment. Results: The 84-month cumulative remission-maintenance and colectomy-free survival rates in the UC patients who were receiving maintenance treatment with thiopurine and 5-aminosalicylate were $43.9 \%$ and $88.0 \%$, respectively. Of the 38 patients who underwent colonoscopy during thiopurine maintenance treatment, 23 (60.5\%) achieved mucosal healing. Of the 59 patients who achieved clinical remission with thiopurine, 6 patients $(10.2 \%)$ discontinued the thiopurine therapy because of adverse events. Conclusions: Our study demonstrates the long-term efficacy and safety of thiopurine treatment in patients with bio-naive UC. (Intest Res 2015;13:250-258)

Key Words: Thiopurine; Colitis, ulcerative; Maintenance treatment

\section{INTRODUCTION}

Ulcerative colitis (UC) is a lifelong immune-mediated inflammatory condition of the colonic mucosa that is characterized by a relapsing and remitting course. ${ }^{1,2}$ Sustained inflammation in patients with UC results in a progressive

Received December 19, 2014. Revised February 19, 2015.

Accepted February 24, 2015.

Correspondence to Hiroshi Nakase, Department of Gastroenterology and Hepatology, Graduate School of Medicine, Kyoto University, 54 Kawaharacho, Shogoin, Sakyo-ku, Kyoto 606-8507, Japan. Tel: +81-75-751-4319, Fax: +81-75-751-4303, E-mail: hiropy_n@kuhp.kyoto-u.ac.jp

Financial support: This work was supported by the Japanese Society for the Promotion of Science "KAKENHI" Grants-in-Aid for Scientific Research (Nos. 24590941, 25860532, 26460967, and 26893122) and Health and Labour Sciences Research Grants for Research on Rare and Intractable Disease from the Ministry of Health, Labour and Welfare, Japan. Conflict of interest: None. worsening of their quality of life. ${ }^{3}$ Most UC patients are successfully managed with mesalamine formulations, but in approximately $25 \%$ of UC patients, mesalamine treatment or other therapies fail, thus requiring intensified treatment or colectomy. ${ }^{4}$ Corticosteroids remain a mainstay for inducing remission in patients with moderate to severe UC, but their long-term use is not recommended because of adverse side effects. ${ }^{5-7}$ The investigators of one European cohort study that included a large number of UC patients reported that at 1 year after withdrawal of corticosteroid treatment, fewer than half of the patients had a sustained response, one-third required colectomy, and approximately one-fourth required reinduction of corticosteroid treatment due to a UC relapse. Thus, the maintenance of steroid-free remission in UC patients is a clinically important issue.

Thiopurines, azathioprine (AZA) and its metabolite

\footnotetext{
(c) Copyright 2015. Korean Association for the Study of Intestinal Diseases. All rights reserved.

This is an Open Access article distributed under the terms of the Creative Commons Attribution Non-Commercial License (http://creativecommons.org/licenses/by-nc/4.0)

which permits unrestricted non-commercial use, distribution, and reproduction in any medium, provided the original work is properly cited.
} 
6-mercaptopurine (6-MP) are purine analogs that effectively induce and maintain remission in patients with IBD, particularly in steroid-refractory or steroid-dependent disease. ${ }^{9,10}$ Although the effects of thiopurine on refractory IBD are apparent in clinical practice, only a few prospective studies and one meta-analysis have been reported. ${ }^{10-12}$ Moreover, little is known about the long-term clinical outcome of UC patients who initially responded to thiopurine treatment.

The efficacy of biologics such as infliximab and adalimumab for induction of remission and maintenance in UC patients has been reported. ${ }^{13-16}$ Clinical trials, case series, and a meta-analysis have demonstrated the benefits of these biologic therapies for UC patients. ${ }^{13-19}$ The costliness of the longterm use of biologics, however, is problematic. ${ }^{20}$ In addition, observational data suggest that patients taking biologics are at increased risk of opportunistic infection. ${ }^{21}$ Therefore, the usefulness of thiopurine for maintaining remission in UC patients must be reconsidered. The aim of this study was to assess the long-term efficacy and safety of maintenance treatment with thiopurine in Japanese patients with UC.

\section{METHODS}

\section{Study Design}

This was a single-center retrospective cohort study. All patients with UC at Kyoto University Hospital who were treated with a thiopurine and 5-aminosalicylate (5-ASA) formulation as maintenance treatment after induction treatments such as 5-ASA, corticosteroids, granulocyte-monocyte adsorption apheresis (GMAA), and calcineurin inhibitors between December 1998 and August 2013 were enrolled in the study. All of the subjects provided informed consent. The study protocol conformed to the Declaration of Helsinki and was approved by the Institutional Review Board at Kyoto University Hospital.

\section{Definition of UC}

The diagnosis of UC was confirmed by reviewing endoscopic and pathological reports. Disease activity was evaluated based on a modified Truelove and Witts Severity Index (MTWSI) score (Supplemental Table 1). ${ }^{22-24}$ Clinical remission was defined as an MTWSI score lower than 4. UC relapse was defined as an MTWSI score increase of at least 3 points from baseline leading to treatment modification. UC flare-up was defined as an increase in MTWSI score of at least 3 points from the baseline and leading to treatment modification. ${ }^{24}$ Refractory UC was defined as (1) steroid refractory, or the lack of a clinical response to a systemic daily dose of $30 \mathrm{mg}$ or more of prednisolone over at least 2 weeks; and (2) steroid dependency, or failing to taper the prednisolone dose to less than $10 \mathrm{mg} /$ day within 12 weeks or relapse within 12 weeks after prednisolone discontinuation. Mucosal healing was defined as endoscopic findings with a Mayo score of 0 or $1 .{ }^{13}$ The time to colonoscopy was different for each patient because this study was retrospective.

To assess mucosal healing, follow-up colonoscopy was routinely performed after clinical remission in UC patients whose corticosteroid dose were completely tapered off.

AZA and 6-MP were administered as thiopurines. We generally administered AZA, and we used 6-MP in patients intolerant to AZA. The thiopurine dose was optimized to achieve a white blood cell count between 3,000 and $5,000 / \mu \mathrm{L}$ or a 6-thioguanine nucleotide concentration between 235 and $450 \mathrm{pmol} / 8 \times 10^{8}$ erythrocytes. For UC patients enrolled in this study, induction treatments included 5-ASA, corticosteroids, GMAA, and calcineurin inhibitors such as tacrolimus and cyclosporine. The tacrolimus dose was adjusted to produce consistent trough levels of 10 to $15 \mathrm{ng} / \mathrm{mL}$, and the dose of cyclosporine was adjusted to produce consistent trough levels of 150 to $250 \mathrm{ng} / \mathrm{mL}$.

\section{Assessment}

The primary endpoint of this study was the remissionmaintenance rate with thiopurine and 5-ASA in the UC patients. Secondary endpoints were the predictive factors, namely flare-up, mucosal healing rate, and colectomy-free survival in UC patients treated with thiopurine and 5-ASA.

\section{Statistical Analysis}

Normally distributed continuous variables were analyzed by using Student's $t$-test, and nonparametric data were analyzed with Wilcoxon's rank sum test. Categorical variables were analyzed by using Pearson's chi-square test or Fisher's exact test if any cell number was less than 5 . A $P<0.05$ was considered as statistically significant. Cumulative colectomy-free and remission-maintenance rates were assessed by using the Kaplan-Meier method, and groups were compared by using the log-rank test stratified by study. Predictive factors were analyzed with multivariate statistics by using Cox regression. All analyses were performed by using the Statview software (SAS Institute, Cary, NC, USA). 


\section{RESULTS}

\section{Patient Characteristics}

Of the 87 UC patients who received various induction therapies, including 5-ASA, GMAA, corticosteroids, or calcineurin inhibitors, 68 (78.2\%) achieved a clinical response with induction treatment and thiopurine. Of the 68 patients, 59 (67.8\%) maintained clinical remission with thiopurine and 5-ASA after tapering the dose in the induction treatment (Fig. 1A). Of these 59 patients, 3 (5.1\%) discontinued thiopurine treatment because of adverse events, and the remaining 56 patients (94.9\%) were evaluated in the present study.

The characteristics of the 56 patients who were undergo- ing maintenance therapy with thiopurine and 5-ASA are shown in Table 1. Of the 56 patients, 38 (67.9\%) were men and $18(32.2 \%)$ were women, with a median age of 31.5 years (range, 13-83 years). The median disease duration from diagnosis of UC to initiation of thiopurine treatment was 33.5 months (range, 1-292 months). Three of the 56 patients (5.4\%) had proctitis, 16 (28.6\%) had left-sided colitis, and the remaining 37 (66.0\%) had extensive colitis. Of the 56 patients, 39 (69.6\%) had refractory UC (steroid dependent in 30 patients [76.9\%] and steroid refractory in 9 patients [23.1\%]). The median MTWSI score at the initiation of the thiopurine treatment was 5.0 points (range, $0-13$ points). The median Mayo endoscopic score at the time of thiopurine initiation was 2.0 points (range, $1-3$ points). In 52 (94.5\%) of the 56
A

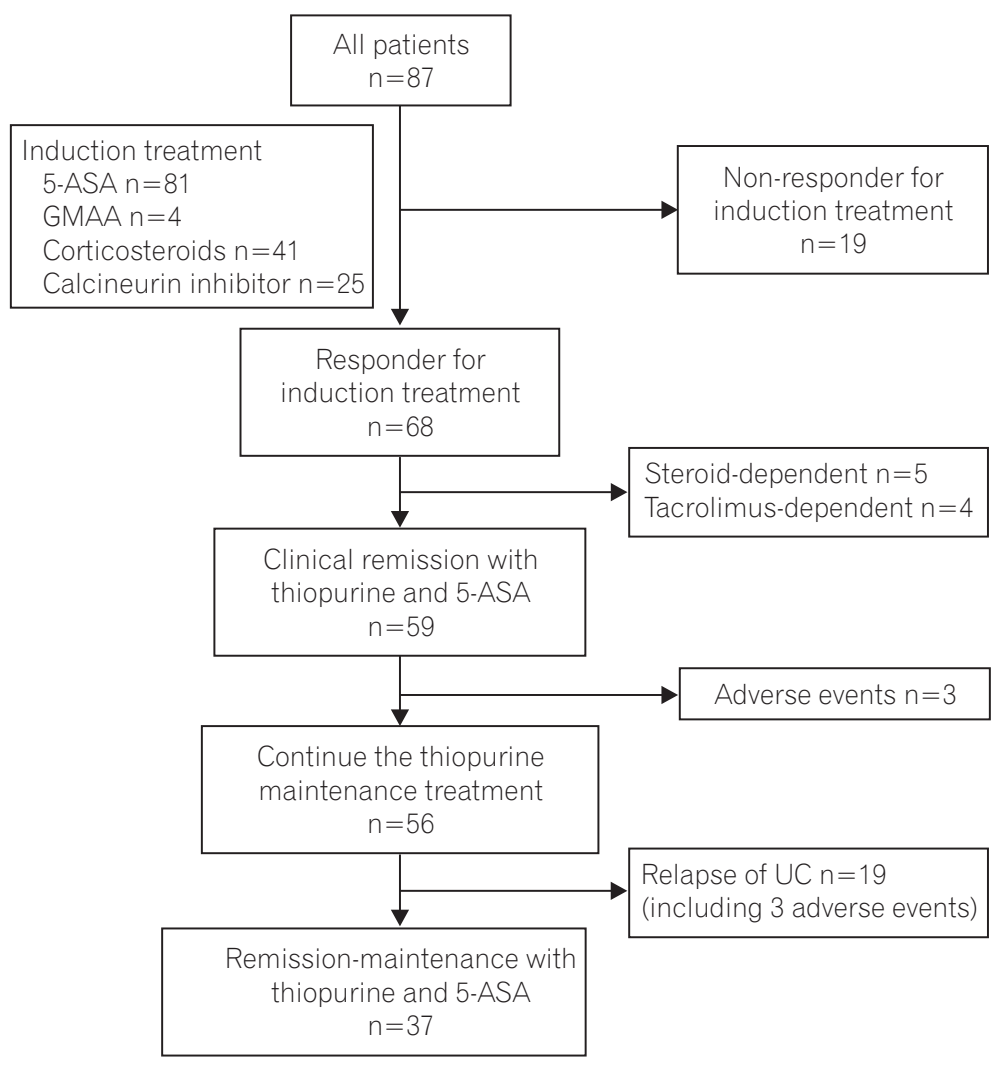

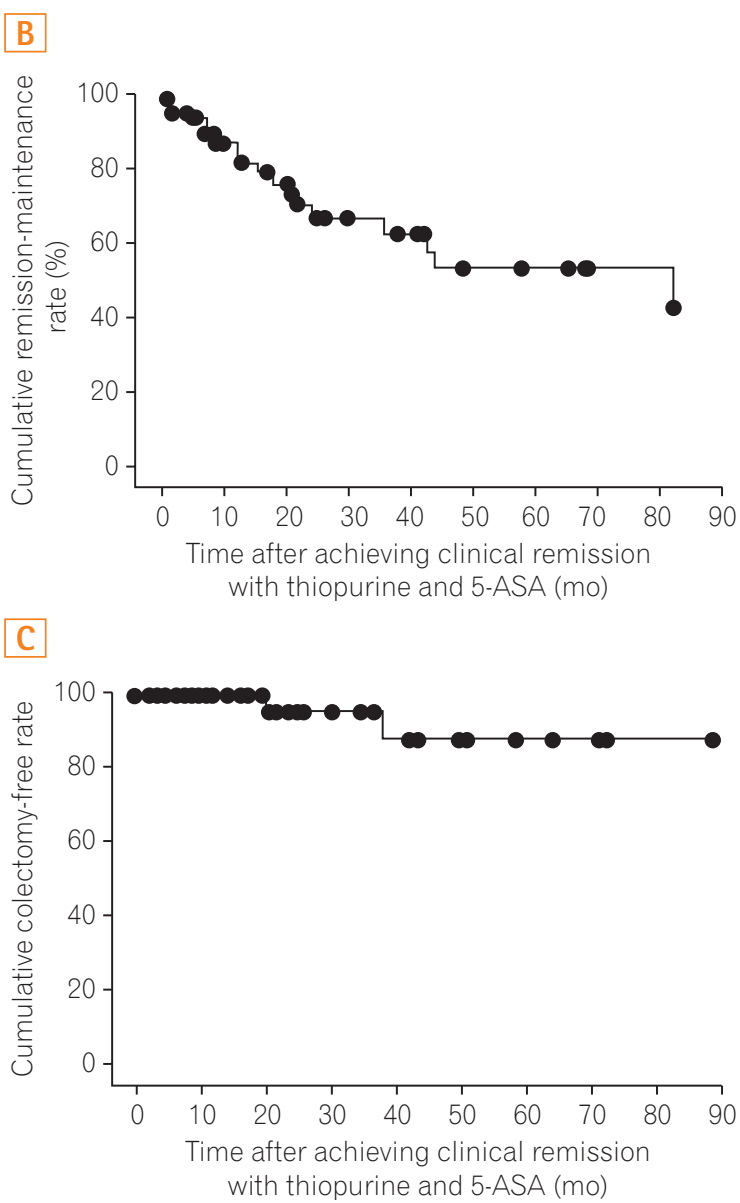

Fig. 1. Flow chart and cumurative remission maintenance and colectomy-free rate. (A) Clinical course of the patients with UC who were enrolled in this study. Of the 87 patients with UC who received various induction therapies, including 5-aminosalicylate (5-ASA), granulocyte-monocyte adsorption apheresis (GMAA), corticosteroids, and calcineurin inhibitors, 68 (78.2\%) achieved a clinical response with induction treatment and thiopurine. Fifty-nine patients (67.8\%) achieved clinical remission with thiopurine and 5-ASA after tapering the dose in the induction treatment, and 56 patients (64.4\%) continued maintenance treatment with thiopurine. (B) Cumulative remission-maintenance rate. The cumulative remission-maintenance rate in 59 patients treated with thiopurine and 5-ASA after tapering the dose in the induction treatment was estimated to be $43.9 \%$ at 84 months. (C) Survival. The cumulative colectomy-free survival rate in the UC patients whose remission was maintained with thiopurine and 5-ASA was estimated to be $88.0 \%$ at 84 months. 
Table 1. Demographic and Clinical Characteristics of the Patients With UC and the Patients in the Remission and Relapse Groups Treated With Thiopurine and 5-Aminosalicylate (5-ASA)

\begin{tabular}{|c|c|c|c|c|}
\hline & $\begin{array}{c}\text { All } \\
(n=56)\end{array}$ & $\begin{array}{c}\text { Remission group } \\
(n=37)\end{array}$ & $\begin{array}{c}\text { Relapse group } \\
(n=19)\end{array}$ & $P$-value \\
\hline Sex (men/women) & 38 (67.9)/18 (32.2) & $25(67.6) / 12(32.4)$ & $13(68.4) / 6(31.6)$ & 0.940 \\
\hline Age $(y r)$ & $31.5(13.0-83.0)$ & $36.0(13.0-83.0)$ & $26.0(18.0-56.0)$ & 0.070 \\
\hline Disease duration $(\mathrm{mo})^{*}$ & $33.5(1.0-292.0)$ & $40.0(1.0-292.0)$ & $15.0(1.0-110.0)$ & 0.080 \\
\hline Modified Truelove and Witts Severity Index* & $5.0(1.0-13.0)$ & $5.0(1.0-13.0)$ & $5.0(2.0-10.0)$ & 1.000 \\
\hline Mayo score (endoscopy)* & $2.0(1.0-3.0)$ & $2.0(1.0-3.0)$ & $3.0(1.0-3.0)$ & 0.340 \\
\hline \multicolumn{5}{|l|}{ Extent of disease } \\
\hline Proctitis & $3(5.4)$ & $3(8.1)$ & $0(0.0)$ & 0.240 \\
\hline Left-side type & $16(28.6)$ & $14(37.8)$ & $2(10.5)$ & 0.070 \\
\hline Extensive colitis & $37(66.0)$ & $20(54.1)$ & $17(89.5)$ & 0.020 \\
\hline Refractory UC & $39(69.6)$ & $25(64.1)$ & $14(82.4)$ & 0.170 \\
\hline \multicolumn{5}{|l|}{ Induction treatment } \\
\hline Concomitant use of 5-ASA & $52(94.5)$ & $35(94.6)$ & $17(89.5)$ & 0.480 \\
\hline GMAA & $4(7.1)$ & $2(5.1)$ & $2(11.8)$ & 0.380 \\
\hline Corticosteroids & $26(46.4)$ & $14(35.9)$ & $12(70.6)$ & 0.020 \\
\hline Calcineurin-inhibitor & $14(25.0)$ & $10(25.6)$ & $4(23.5)$ & 0.910 \\
\hline History of treatment with a corticosteroid dosage $\geq 40 \mathrm{mg} /$ day & $20(35.7)$ & $8(20.5)$ & $12(70.6)$ & $<0.001$ \\
\hline \multicolumn{5}{|l|}{ Laboratory examination } \\
\hline White blood cell count $(/ \mu \mathrm{L})$ & $6,500(4,100-14,600)$ & $6,450(4,100-13,100)$ & $6,950(5,200-14,600)$ & 0.580 \\
\hline Hemoglobin level (g/dL) & $12.1(8.2-15.2)$ & $12.0(8.2-14.8)$ & $12.6(9.2-15.2)$ & 0.590 \\
\hline MCV delta values for 3 months after initiating thiopurines (fL) & $2.5(-6.9$ to 14.8$)$ & $2.8(-6.9$ to 14.8$)$ & $0.8(-6.9$ to 9.1$)$ & 0.240 \\
\hline CRP concentration (mg/dL) & $0.3(0.0-3.3)$ & $0.3(0-3.3)$ & $0.3(0.0-1.0)$ & 0.480 \\
\hline
\end{tabular}

The numbers of patients are shown, and the \% values are percentages of the total available data.

*Data are presented as median (range). The $P$-value was evaluated between the remission and relapse groups.

GMAA, granulocyte-monocyte adsorption apheresis; MCV, mean corpuscular volume.

patients, 5-ASA was used for induction treatment. GMAA was used in 4 (7.1\%), corticosteroids in 26 (46.4\%), and a calcineurin inhibitor (tacrolimus/cyclosporine) in 14 (25.0\%).

\section{Clinical Remission Maintenance in UC Patients Who Were Receiving Thiopurine and 5-ASA as Mainte- nance Treatment}

Of the 56 patients, 47 (83.9\%) were treated with AZA and 9 (16.1\%) were treated with 6-MP. The median dose of thiopurine during the maintenance treatment was $50 \mathrm{mg}$ (range, $10-135 \mathrm{mg}$ ), although 4 patients $(7.1 \%)$ received concomitant allopurinol to increase the 6-thioguanine nucleotide concentration. 6-Thioguanine nucleotide concentration was evaluated in 37 (66.1\%) of the 56 patients, and the median 6-thioguanine nucleotide concentration was 358.8 $\mathrm{pmol} / 8 \times 10^{8}$ erythrocytes (range, $50-1,670 \mathrm{pmol} / 8 \times 10^{8}$ erythrocytes). In addition, 52 (94.5\%) of the 56 patients received concomitant 5-ASA, and the median 5-ASA dose was 3,000 $\mathrm{mg}$ (range, 250-4,000 mg) during thiopurine maintenance treatment.

Of the 56 patients, 37 (66.1\%) were maintained in clinical remission with thiopurine and 5-ASA (remission group), while 19 (33.9\%) had a UC relapse during the study period (relapse group). Six UC patients discontinued thiopurine due to adverse events. However, 3 of them experienced a UC 
relapse at the onset of adverse events and were included in the relapse group (Fig. 1A). The median follow-up duration after initiating thiopurine in the 56 patients who achieved clinical remission was 33.0 months (range, 4-143 months). Based on the Kaplan-Meier analysis, the cumulative remission-maintenance rates in the 56 patients treated with thio- purine and 5-ASA after the dose in the induction treatment was tapered were estimated to be $43.9 \%$ at 84 months, $94.3 \%$ at 6 months, $84.6 \%$ at 12 months, $69.0 \%$ at 24 months, $54.9 \%$ at 48 months, $54.9 \%$ at 72 months, and $43.9 \%$ at 84 months, respectively (Fig. 1B).

Table 2. Predictive Factors of Remission Maintenance With Thiopurine and 5-Aminosalicylate Treatment

\begin{tabular}{lccc}
\hline & Hazard ratio & $\mathbf{9 5 \%} \mathbf{C l}$ & $\boldsymbol{P}$-value \\
\hline Age & 1.02 & $0.98-1.06$ & 0.90 \\
Disease duration & 0.99 & $0.98-1.00$ & 0.98 \\
Left-sided colitis & 0.24 & $0.05-1.11$ & 0.07 \\
Induction treatment with corticosteroids & 0.72 & $0.25-2.09$ & 0.54 \\
No history of treatment with a corticosteroid dosage $\geq 40 \mathrm{mg} /$ day & 3.76 & $1.30-10.88$ & 0.01 \\
\hline
\end{tabular}

Every item was evaluated at the time thiopurine treatment was initiated.

Table 3. Demographic and Clinical Characteristics of the Patients With UC Treated With Thiopurine and 5-Aminosalicylate (5-ASA) in the Mucosal Healing and Non-Mucosal Healing Groups

\begin{tabular}{|c|c|c|c|}
\hline & $\begin{array}{l}\text { Mucosal healing } \\
(n=23)\end{array}$ & $\begin{array}{c}\text { Non-mucosal healing } \\
(n=15)\end{array}$ & $P$-value \\
\hline Sex (men/women) & $16(69.6) / 7(30.4)$ & $10(66.7) / 5(33.3)$ & 0.85 \\
\hline Age (yr) & $41.0(18.0-83.0)$ & $28.0(20-58)$ & 0.07 \\
\hline Disease duration (mo)* & $28.0(1.0-151.0)$ & $63.0(1.0-292.0)$ & 0.24 \\
\hline Modified Truelove and Witts Severity Index* & $5.0(1.0-10.0)$ & $5.0(1.0-13.0)$ & 0.85 \\
\hline Mayo score (endoscopy)* & $3.0(1.0-3.0)$ & $2.0(1.0-3.0)$ & 0.89 \\
\hline \multicolumn{4}{|l|}{ Extent of disease } \\
\hline Proctitis & $1(4.4)$ & $1(6.7)$ & 0.75 \\
\hline Left sided type & $5(21.7)$ & $5(33.3)$ & 0.43 \\
\hline Extensive colitis & $17(73.9)$ & $9(60.0)$ & 0.37 \\
\hline Refractory UC & $17(73.9)$ & $9(60.0)$ & 0.37 \\
\hline \multicolumn{4}{|l|}{ Induction treatment } \\
\hline 5-ASA & $22(95.7)$ & $14(93.3)$ & 0.75 \\
\hline GMAA & $2(8.7)$ & $0(0.0)$ & 0.24 \\
\hline Corticosteroids & $7(56.5)$ & $10(66.6)$ & 0.55 \\
\hline Calcineurin-inhibitor & $6(2.6)$ & $4(26.7)$ & 0.63 \\
\hline History of treatment with a corticosteroid dosage $\geq 40 \mathrm{mg} /$ day & $7(56.5)$ & $8(80.0)$ & 0.16 \\
\hline \multicolumn{4}{|l|}{ Laboratory examination } \\
\hline White blood cell count $(/ \mu \mathrm{L})$ & $6,450(4,000-14,600)$ & $7,300(4,500-13,100)$ & 0.66 \\
\hline Hemoglobin level (g/dL) & $12.3(8.2-14.8)$ & $12.2(9.0-15.2)$ & 0.85 \\
\hline MCV delta values 3 months after initiating thiopurines (fL) & $3.0(-6.9$ to 12.3$)$ & $2.6(-6.9$ to 9.0$)$ & 0.34 \\
\hline CRP concentration (mg/dL) & $0.5(0.1-2.3)$ & $1.1(0.0-6.6)$ & 0.12 \\
\hline
\end{tabular}

The numbers of patients are shown, and the \% values are percentages of the total available data.

${ }^{*}$ Data are presented as mean \pm standard deviation values.

GMAA, granulocyte-monocyte adsorption apheresis; MCV, mean corpuscular volume. 
Table 4. Predictive Alaility of Mucosal Healing With Thiopurine and 5-Aminosalicylate Treatment

\begin{tabular}{|c|c|c|c|}
\hline & Hazard ratio & $95 \% \mathrm{Cl}$ & $P$-value \\
\hline Age & 0.99 & $0.93-1.04$ & 0.63 \\
\hline Disease duration & 1.01 & $0.99-1.02$ & 0.83 \\
\hline No history of treatment with a corticosteroid dosage $\geq 40 \mathrm{mg} /$ day & 3.81 & $0.88-16.42$ & 0.07 \\
\hline Serum CRP & 1.46 & $1.03-2.06$ & 0.03 \\
\hline
\end{tabular}

Every item was evaluated at the time thiopurine treatment was initiated.

\section{Predictive Factors of Maintaining Remission With Thiopurine}

To evaluate the predictive factors of maintaining remission with thiopurine, we evaluated the differences in the patient characteristics between the remission and relapse groups. The number of UC patients with a history of corticosteroid use ( $\geq 40 \mathrm{mg} /$ day) differed significantly between the remission and relapse groups (Table 1). According to the KaplanMeier analysis, the cumulative remission-maintenance rate was significantly lower in the UC patients with than in those without a history of treatment with a corticosteroid dosage $\geq 40 \mathrm{mg} /$ day (12.1\% at 83 months vs. $51.5 \%$ at 84 months, $P=0.032$ ). Moreover, the multivariate analysis using Cox regression suggested that history of treatment with a corticosteroid dosage $\geq 40 \mathrm{mg}$ /day was indicated as a negative predictive factor of clinical remission maintenance in UC patients (hazard ratio, 3.76; $P=0.01$ ) (Table 2).

\section{Mucosal Healing for UC Patients Receiving Mainten- ance Treatment With Thiopurine and 5-ASA}

Of the 56 UC patients, 38 (67.9\%) underwent colonoscopy to evaluate mucosal healing, and the median time to assessing mucosal healing after initiating thiopurine agents was 26.8 months (range, 1-84 months). Among the 38 patients, $23(60.5 \%)$ achieved mucosal healing (mucosal healing group) and 15 (39.5\%) did not achieve mucosal healing (non-mucosal healing group). To evaluate the predictive factors of mucosal healing in the UC patients who maintained clinical remission with thiopurine, we analyzed the differences in patient characteristics between the mucosal and non-mucosal healing groups. The serum CRP concentration and number of UC patients with a history of corticosteroid treatment $\geq 40 \mathrm{mg} /$ day tended to be greater in the nonmucosal healing group than in the mucosal healing group, although no significant differences in patient characteristics were observed between the mucosal and non-mucosal
Table 5. Adverse Events During the Study Period According to Treatment With Thiopurine and 5-Aminosalicylate

\begin{tabular}{lc}
\hline & Adverse events \\
\hline Death & 0 \\
Infections & 1 \\
Pneumonia & 1 \\
Infectious mononucleosis & \\
Gastroenterology and hepatology & 4 \\
Nausea & 4 \\
Liver dysfunction & 1 \\
Pancreatitis & \\
Hematology & 3 \\
Leukopenia & 2 \\
Anemia & \\
Dermatology & 1 \\
Depilation & $17(28.8)$ \\
Total events
\end{tabular}

The numbers of adverse events are shown, not the numbers of patients, and $\%$ values are percentage of total of available data.

healing groups (Table 3). Based on the multivariate analysis (Table 4), CRP elevation was a negative factor of mucosal healing (hazard ratio, $1.46 ; P=0.03$ ).

\section{Colectomy-Free Rate Among UC Patients Who Achi- eved Steroid-Free Remission With Thiopurine and 5-ASA}

Of the 56 patients, $2(3.6 \%)$ underwent colectomy due to a UC relapse under steroid-free remission. Based on the Kaplan-Meier analysis, the estimated cumulative colectomyfree rate of the UC patients whose remission was maintained with thiopurine was $88.0 \%$ at 84 months (Fig. 1C). 


\section{Adverse Events}

Adverse events occurred in 17 (28.8\%) of the 59 patients who achieved clinical remission with thiopurine and 5-ASA (Table 5). Moreover, 6 (10.2\%) of the 59 patients discontinued thiopurine treatment because of adverse events. Adverse events requiring withdrawal of thiopurine treatment included infectious mononucleosis (1 patient, 1.7\%), nausea (1 patients, 1.7\%), liver dysfunction (2 patients, $3.4 \%$ ), pancreatitis (1 patient, $1.7 \%$ ), and leukopenia (1 patients, $1.7 \%$ ). All of the patients recovered from adverse events upon discontinuation of thiopurine, and no mortality due to adverse events occurred during the follow-up.

\section{DISCUSSION}

The findings of the present study demonstrate the longterm efficacy and safety of thiopurine for maintaining remission in bio-naive UC patients. A history of treatment with high-dose corticosteroids affects both the maintenance of remission and mucosal healing in bio-naive UC patients treated with thiopurine.

Recently, many papers reported the efficacy of biologics for the induction and maintenance of remission in refractory UC patients. ${ }^{13-19}$ Induction and maintenance of long-term remission in patients with mild to moderate bio-naive UC, however, should also be considered. Controlled studies have demonstrated that thiopurines are effective for steroid tapering and maintenance of remission in UC patients. ${ }^{11}$ Several meta-analyses also demonstrated the efficacy of thiopurine for the induction and maintenance of remission in UC.-12,25,26 In the present study, clinical remission was maintained with thiopurine in $66.1 \%$ of the bio-naive UC patients, suggesting the high efficacy of thiopurine for maintenance of remission in UC patients.

The identification of UC patients in whom clinical remission can be maintained with thiopurine is highly important for long-term treatment of UC. Nquyen et al. reported that factors such as age, sex, patient adherence, duration of treatment with thiopurine, erythrocyte count, and erythrocyte sedimentation rate could not predict the efficacy of thiopurine. ${ }^{27}$ Interestingly, our data revealed that corticosteroid treatment, particularly in those with a history of high-dose corticosteroid use, might be a negative predictive factor of maintaining remission with thiopurine in UC patients. Thus, high-dose corticosteroids should be avoided for successful management of UC patients.

The aims of UC treatment should include the promotion of mucosal healing and the induction and maintenance of clinical remission, because several reports indicate that mucosal healing reduces the rate of hospitalization and colectomy, improving patient quality of life. ${ }^{13,28,29}$ Data regarding the usefulness of thiopurine for achieving and maintaining mucosal healing in UC patients, however, are limited. In a cohort study with a small number of UC patients reported by Lopez et al., $60 \%$ of UC patients who maintained remission with thiopurine also achieved and maintained mucosal healing. ${ }^{28}$ Endoscopic activity might be predictive of flareup in UC patients, even if clinical remission is maintained. The present study revealed that the mucosal healing rate in UC patients who maintained remission with thiopurine treatment (60.5\%) was similar to that in the study of Lopez et $\mathrm{al}^{28}$ and suggests that a high CRP concentration is a negative predictor of mucosal healing. Previous studies demonstrated the positive correlation between CRP level and the drgree of mucosal inflammation evaluated by using endoscopy, especially in severe UC. ${ }^{30-32}$ High doses and long-term use of corticosteroids could affect epithelial regeneration by inhibiting nuclear factor kappa B activation in epithelial cells, ${ }^{33}$ even if thiopurines are selected for maintenance treatment. In this regard, the use of high-dose corticosteroids for the treatment of UC should be avoided as much as possible.

Previous reports indicated that treatment with thiopurine may increase the risk of life-threatening adverse events, particularly malignancies. ${ }^{34-37}$ The guidelines of the European Crohn's and Colitis Organization, however, recommend thiopurine as a first-line treatment for refractory UC patients who experience a UC flare-up during corticosteroid withdrawal. ${ }^{38}$ In the present study, adverse events occurred in $27.1 \%$ of the UC patients treated with thiopurine. The frequency of adverse events in our study was similar to that in previous reports ${ }^{26,34,35}$ Moreover, no life-threatening infections or malignancies occurred in the observational period (7 years). Roblin et al..$^{39}$ reported that an optimal dose of thiopurine might help to prevent severe adverse events. Therefore, monitoring 6-thioguanine nucleotide levels is required for maintenance of long-term remission and the prevention of adverse events in UC patients treated with thiopurine.

The present study has several limitations, including the small number of patients and the single-center, retrospective design. In addition, the time to assess endoscopic activity after achieving clinical remission varied. Therefore, our data should be interpreted with caution, and further studies with a larger number of enrolled patients are required.

In conclusion, our long-term observational data indicate that thiopurine is useful for maintaining remission and pro- 
moting mucosal healing in bio-naive UC patients. Optimal use of thiopurine will contribute to long-term remission in bio-naive UC patients.

\section{REFERENCES}

1. MacDermott RP, Stenson WF. Alterations of the immune system in ulcerative colitis and Crohn's disease. Adv Immunol 1988;42:285-328.

2. Monteleone I, Vavassori P, Biancone L, Monteleone G, Pallone F. Immunoregulation in the gut: success and failures in human disease. Gut 2002;50(Suppl 3):III60- III64.

3. Hanauer SB. Review article: evolving concepts in treatment and disease modification in ulcerative colitis. Aliment Pharmacol Ther 2008;27(Suppl 1):15-21.

4. Sutherland LR, Martin F, Bailey RJ, et al. A randomized, placebo-controlled, double-blind trial of mesalamine in the maintenance of remission of Crohn's disease. The Canadian Mesalamine for Remission of Crohn's Disease Study Group. Gastroenterology 1997;112:1069-1077.

5. Kozuch PL, Hanauer SB. Treatment of inflammatory bowel disease: a review of medical therapy. World J Gastroenterol 2008;14:354-377.

6. Carter MJ, Lobo AJ, Travis SP; IBD Section, British Society of Gastroenterology. Guidelines for the management of inflammatory bowel disease in adults. Gut 2004;53(Suppl 5):V1-V16.

7. Irving PM, Gearry RB, Sparrow MP, Gibson PR. Review article: appropriate use of corticosteroids in Crohn's disease. Aliment Pharmacol Ther 2007;26:313-329.

8. Faubion WA, Jr., Loftus EV, Jr., Harmsen WS, Zinsmeister AR, Sandborn WJ. The natural history of corticosteroid therapy for inflammatory bowel disease: a population-based study. Gastroenterology 2001;121:255-260.

9. Costantino G, Furfaro F, Belvedere A, Alibrandi A, Fries W. Thiopurine treatment in inflammatory bowel disease: response predictors, safety, and withdrawal in follow-up. J Crohns Colitis 2012;6:588-596

10. Chebli LA, Chaves LD, Pimentel FF, et al. Azathioprine maintains long-term steroid-free remission through 3 years in patients with steroid-dependent ulcerative colitis. Inflamm Bowel Dis 2010;16:613-619.

11. Ardizzone S, Maconi G, Russo A, Imbesi V, Colombo E, Bianchi Porro G. Randomised controlled trial of azathioprine and 5-aminosalicylic acid for treatment of steroid dependent ulcerative colitis. Gut 2006;55:47-53.

12. Timmer A, McDonald JW, Macdonald JK. Azathioprine and 6-mercaptopurine for maintenance of remission in ulcerative colitis. Cochrane Database Syst Rev doi: 10.1002/14651858. CD000478.pub2. Published online 24 January 2007.
13. Rutgeerts P, Sandborn WJ, Feagan BG, et al. Infliximab for induction and maintenance therapy for ulcerative colitis. $\mathrm{N}$ Engl J Med 2005;353:2462-2476.

14. Probert CS, Hearing SD, Schreiber S, et al. Infliximab in moderately severe glucocorticoid resistant ulcerative colitis: a randomised controlled trial. Gut 2003;52:998-1002.

15. Reinisch W, Sandborn WJ, Hommes DW, et al. Adalimumab for induction of clinical remission in moderately to severely active ulcerative colitis: results of a randomised controlled trial. Gut 2011;60:780-787.

16. Sandborn WJ, van Assche G, Reinisch W, et al. Adalimumab induces and maintains clinical remission in patients with moderate-to-severe ulcerative colitis. Gastroenterology 2012;142:257265.

17. Stidham RW, Lee TC, Higgins PD, et al. Systematic review with network meta-analysis: the efficacy of anti-tumour necrosis factor-alpha agents for the treatment of ulcerative colitis. Aliment Pharmacol Ther 2014;39:660-671.

18. Sandborn WJ, Feagan BG, Marano C, et al. Subcutaneous golimumab induces clinical response and remission in patients with moderate-to-severe ulcerative colitis. Gastroenterology 2014;146:85-95.

19. Sandborn WJ, Feagan BG, Marano C, et al. Subcutaneous golimumab maintains clinical response in patients with moderateto-severe ulcerative colitis. Gastroenterology 2014;146:96-109.

20. Dretzke J, Edlin R, Round J, et al. A systematic review and economic evaluation of the use of tumour necrosis factor-alpha (TNF-alpha) inhibitors, adalimumab and infliximab, for Crohn's disease. Health Technol Assess 2011;15:1-244.

21. Ford AC, Peyrin-Biroulet L. Opportunistic infections with antitumor necrosis factor-alpha therapy in inflammatory bowel disease: meta-analysis of randomized controlled trials. Am J Gastroenterol 2013;108:1268-1276.

22. Lichtiger S, Present DH, Kornbluth A, et al. Cyclosporine in severe ulcerative colitis refractory to steroid therapy. N Engl J Med 1994;330:1841-1845.

23. Yamamoto S, Nakase H, Mikami S, et al. Long-term effect of tacrolimus therapy in patients with refractory ulcerative colitis. Aliment Pharmacol Ther 2008;28:589-597.

24. Laharie D, Bourreille A, Branche J, et al. Ciclosporin versus infliximab in patients with severe ulcerative colitis refractory to intravenous steroids: a parallel, open-label randomised controlled trial. Lancet 2012;380:1909-1915.

25. Gisbert JP, Linares PM, McNicholl AG, Maté J, Gomollón F. Meta-analysis: the efficacy of azathioprine and mercaptopurine in ulcerative colitis. Aliment Pharmacol Ther 2009;30:126-137. 
26. Khan KJ, Dubinsky MC, Ford AC, Ullman TA, Talley NJ, Moayyedi P. Efficacy of immunosuppressive therapy for inflammatory bowel disease: a systematic review and meta-analysis. Am J Gastroenterol 2011;106:630-642.

27. Nguyen TV, Vu DH, Nguyen TM, Lachaux A, Boulieu R. Exploring associations of 6-thioguanine nucleotide levels and other predictive factors with therapeutic response to azathioprine in pediatric patients with IBD using multilevel analysis. Inflamm Bowel Dis 2013;19:2404-2410.

28. López-Palacios N, Mendoza JL, Taxonera C, Lana R, LópezJamar JM, Díaz-Rubio M. Mucosal healing for predicting clinical outcome in patients with ulcerative colitis using thiopurines in monotherapy. Eur J Intern Med 2011;22:621-625.

29. Dave M, Loftus EV, Jr. Mucosal healing in inflammatory bowel disease-a true paradigm of success? Gastroenterol Hepatol (N Y) 2012;8:29-38.

30. Rosenberg L, Nanda KS, Zenlea T, et al. Histologic markers of inflammation in patients with ulcerative colitis in clinical remission. Clin Gastroenterol Hepatol 2013;11:991-996.

31. Solem CA, Loftus EV, Jr., Tremaine WJ, Harmsen WS, Zinsmeister AR, Sandborn WJ. Correlation of C-reactive protein with clinical, endoscopic, histologic, and radiographic activity in inflammatory bowel disease. Inflamm Bowel Dis 2005;11:707712.

32. Schoepfer AM, Beglinger C, Straumann A, Trummler M, Renzulli P, Seibold F. Ulcerative colitis: correlation of the Rachmilewitz endoscopic activity index with fecal calprotectin, clinical activity, C-reactive protein, and blood leukocytes. Inflamm Bowel Dis 2009;15:1851-1858.
33. Schreiber S, Nikolaus S, Hampe J. Activation of nuclear factor kappa B inflammatory bowel disease. Gut 1998;42:477-484.

34. Chaparro M, Ordás I, Cabré E, et al. Safety of thiopurine therapy in inflammatory bowel disease: long-term follow-up study of 3931 patients. Inflamm Bowel Dis 2013;19:1404-1410.

35. Qasim A, McDonald S, Sebastian S, et al. Efficacy and safety of 6-thioguanine in the management of inflammatory bowel disease. Scand J Gastroenterol 2007;42:194-199.

36. Khan N, Abbas AM, Lichtenstein GR, Loftus EV, Jr., Bazzano LA Risk of lymphoma in patients with ulcerative colitis treated with thiopurines: a nationwide retrospective cohort study. Gastroenterology 2013;145:1007-1015.

37. Beaugerie L, Brousse N, Bouvier AM, et al. Lymphoproliferative disorders in patients receiving thiopurines for inflammatory bowel disease: a prospective observational cohort study. Lancet 2009;374:1617-1625.

38. Travis SP, Stange EF, Lémann M, et al. European evidencebased consensus on the management of ulcerative colitis: current management. J Crohns Colitis 2008;2:24-62.

39. Roblin X, Peyrin-Biroulet L, Phelip JM, Nancey S, Flourie B. A 6-thioguanine nucleotide threshold level of $400 \mathrm{pmol} / 8 \times 10(8)$ erythrocytes predicts azathioprine refractoriness in patients with inflammatory bowel disease and normal TPMT activity. Am J Gastroenterol 2008;103:3115-3122. 
Supplemental Table 1. Modified Truelove and Witts Severity Index Score

\begin{tabular}{|c|c|c|c|c|c|c|}
\hline Score & 0 & 1 & 2 & 3 & 4 & 5 \\
\hline Bowel movement & $0-2$ & $3-4$ & $5-6$ & $7-9$ & $\leq 10$ & \\
\hline Nocturnal diarrhea & No & Yes & & & & \\
\hline Visible blood in stool (\%) & 0 & $<50$ & $\leq 50$ & 100 & & \\
\hline Abdominal tenderness & None & Mild & Moderate & Severe & & \\
\hline Abdominal pain/cramping & None & Mild & Moderate & Severe & & \\
\hline Need for antidiarrheals & No & Yes & & & & \\
\hline General status & Perfect & Very good & Good & Average & Poor & Terrible \\
\hline Fecal incontinence & No & Yes & & & & \\
\hline
\end{tabular}

Severe disease, $\leq 12$; mild to moderate, $5-11$; remission category, $\leq 4$ 